\title{
ANÁLISE DO USO DO CELULAR NO CONTEXTO EDUCACIONAL
}

\author{
Silvia Cristina Freitas Batista, IF Fluminense Campus Campos-Centro \\ silviac@iff.edu.br \\ Gilmara Teixeira Barcelos, IF Fluminense Campus Campos-Centro \\ gilmarab@iff.edu.br
}

\begin{abstract}
RESUMO
Os avanços tecnológicos relacionados aos celulares têm possibilitado que os mesmos realizem diversas funções, com desempenhos cada vez melhores. No entanto, em relação ao uso no contexto educacional, os celulares dividem opiniões, principalmente quando utilizados em sala de aula. Se por um lado esse equipamento pode ser responsável por problemas, como distrações durante a aula, por outro pode apoiar tarefas pedagógicas. Diante desse panorama, o presente artigo visa discutir o uso do celular no contexto educacional e, apoiando a discussão, são analisados dados de uma pesquisa feita com alunos da Licenciatura em Matemática de uma instituição federal. A mesma mostrou que as opiniões dos professores em formação estão coerentes com a literatura da área, sinalizando dificuldades e vantagens do uso do celular na educação.
\end{abstract}

Palavras-chave: celulares, contexto educacional, licenciatura em Matemática.

\section{ANALYSIS OF MOBILE PHONE USE IN EDUCATIONAL CONTEXTS}

\begin{abstract}
Technological advancements related to mobile phones have allowed them to perform many functions with increasingly better performance. However, use of mobile phones in educational contexts is not unanimous, especially when used in the classroom. While this equipment can be responsible for problems, such as distraction during classes, it can also support pedagogical activities. All considered, this paper aims at discussing the use of mobile phones in education with support of data obtained in a survey with undergraduate students of Mathematics Education at a federal institution. Data shows that opinions collected in the research are coherent with the literature, that is, use of mobile phones in education poses difficulties and benefits.
\end{abstract}

Key Words: mobile phones, educational contexts, Mathematics education

\section{Introdução}

Com a crescente portabilidade e convergência funcional de tecnologias, bem como com a redução de custo de produtos e serviços disponíveis, os dispositivos móveis tornam-se cada vez mais presentes no dia a dia das pessoas. A importância crescente desses dispositivos na vida diária tem motivado pesquisas no contexto educacional (Pachler et al., 2010). Mobile learning (m-learning) é o campo de estudo que busca analisar como os dispositivos móveis podem colaborar para a aprendizagem. Em geral, atividades nessa área apresentam características como interatividade, mobilidade, trabalho em equipe, aprendizagens em contextos reais, entre outras (Batista, 2011).

Os recursos presentes nos dispositivos móveis estão cada vez mais potentes e fáceis de usar (Quinn, 2011). Esses dispositivos tendem, então, a proporcionar cada vez mais facilidade de acesso a informações e melhor suporte para aplicativos multimídia e colaborativos (Educause, 2010). 
Na educação formal, no entanto, esses dispositivos, principalmente os celulares, recebem algumas críticas por parte de professores, em relação a problemas que acarretam, tais como distração, desviando o foco dos alunos dos assuntos abordados em sala de aula. Tratando especificamente do uso do celular, Machado (2012) defende que é preciso analisar atentamente a questão. Segundo o autor, tanto pode ser preciso estabelecer restrições de uso desses dispositivos nas escolas, para permitir um melhor andamento das ações pedagógicas e para "desligar" um pouco os alunos do ritmo frenético da vida atual, como é possível tornar este equipamento um elemento de trabalho para o desenvolvimento de diversos projetos educacionais.

Diante desse cenário, o presente artigo visa discutir o uso do celular no contexto educacional. Apoiando essa discussão, são analisados dados de uma pesquisa realizada com alunos da Licenciatura em Matemática de uma instituição federal, com a qual se buscou captar a visão dos mesmos sobre o referido uso. Ressalta-se que a opção pela Licenciatura em Matemática deve-se ao fato de que o estudo descrito foi promovido no âmbito de um projeto de pesquisa cujo foco é analisar o uso de dispositivos móveis na aprendizagem de Matemática. Nesse sentido, a licenciatura em questão tem sido público alvo de diversas ações do referido projeto de pesquisa.

Tendo em vista o objetivo apresentado, discute-se, na seção 2, o uso do celular no contexto educacional, abordando dificuldades e potencialidades do mesmo. Na seção 3, são descritos os procedimentos metodológicos adotados e, na seção 4, são analisados os dados levantados na pesquisa com alunos da Licenciatura em Matemática. Finalizando, na seção 5, são apresentadas algumas considerações sobre o tema abordado.

\section{Celular no contexto educacional: dificuldades e potencialidades}

A popularização dos celulares e o desenvolvimento tecnológico associado aos mesmos têm destacado estes equipamentos em ações relacionadas a m-learning (Schmiedl et al., 2010, Robles et al., 2011, Xie et al., 2011). Pela sua popularidade, os celulares podem contribuir para aumentar o acesso a conteúdos educacionais digitais. Como dispositivos portáteis ${ }^{1}$ que são podem facilitar a aprendizagem em contextos fora dos limites das instituições educacionais, bem como dentro das mesmas (Unesco, 2012). Assim, esses dispositivos têm potencial para tornar o aprendizado mais acessível, colaborativo e relevante (Unesco, 2012).

No entanto, apesar das potencialidades que o celular apresenta em termos educacionais, a escola, em geral, não faz uso das mesmas, optando, muitas vezes, apenas por proibir sua utilização em sala de aula (Seabra, 2013). O referido autor reconhece que o celular pode ser responsável por distrações e possibilitar, com toda a sua tecnologia, práticas de repasse de respostas de provas e testes, de modo muito mais eficiente do que formas tradicionais. Porém, apesar das dificuldades apontadas, Seabra (2013) tem uma visão otimista sobre o uso de celulares na escola e sugere, em relação à questão da distração, que o professor discuta regras de usos aceitáveis com os alunos. O autor destaca que é preciso considerar que mesmo o lápis e papel (e o próprio cérebro) também podem contribuir para distrações, se o aluno não estiver engajado na aula. Quanto à questão do repasse de respostas, o autor recomenda mudança na forma de elaboração de provas e testes.

Machado (2012) também analisa problemas e possibilidades de uso de celulares no ambiente escolar, porém de forma mais ponderada do que Seabra (2013). Para Machado (2012), o toque de um celular, em sala de aula, com variedade de músicas e estilos (muitas vezes cômicos), pode atrapalhar, consideravelmente, o andamento das ações pedagógicas previstas pelo professor. Há também o envio de torpedos com mensagens de texto, que embora uma prática silenciosa, tira o foco dos alunos da aula, e, muitas vezes, é utilizada para envio de respostas de provas ou testes. Além disso, é preciso 
considerar os games, músicas, vídeos, fotos ou acesso à Internet que podem comprometer o desempenho dos alunos em sala de aula (Machado, 2012). Assim, o autor entende que, em geral, o celular deve sofrer algumas restrições de uso nas escolas, mas também afirma que esse equipamento pode colaborar em ações pedagógicas, como ferramenta de pesquisa e produção.

Em relação a alunos da Educação Infantil ou do Ensino Fundamental, Machado (2012) defende que, embora muitos pais presenteiem seus filhos muito novos com celulares, a orientação seja para que qualquer comunicação com a família seja feita com a intermediação da escola e não diretamente pelo celular.

Batista (2011) analisando, de forma conjunta, uma pesquisa exploratória e um estudo de caso sobre o uso educacional do celular, lista aspectos positivos que foram evidenciados nas duas experiências: i) habilidade dos alunos em lidar com o teclado; ii) praticidade; iii) receptividade dos alunos quanto ao uso educacional dos dispositivos. Da mesma forma, a autora também identifica aspectos negativos: i) variedade de modelos e recursos dos celulares; ii) tamanho da tela; iii) custos com conexão à Internet.

As dificuldades relatadas não são específicas de uma área curricular. Da mesma forma, entende-se que as potencialidades desses dispositivos também são gerais, podendo apoiar ações pedagógicas nas mais diversas áreas. Neste artigo, no entanto, são focalizados estudos direcionados à Matemática (Baya'a e Daher, 2009; Ndafenongo, 2011; Kalloo e Mohan, 2012), exemplificando que, mesmo para a área de exatas, estudos têm apontado possibilidades de contribuições dos celulares.

Baya'a e Daher (2009) relatam uma experiência em Matemática realizada com estudantes de uma escola de Israel (8th grade - Middle School), em forma de atividade extraclasse. Os alunos utilizaram aplicativos gráficos para celular ${ }^{2}$, específicos para Matemática (trabalhando com funções) e, também, recursos dos próprios dispositivos, como fotografias, vídeos, entre outros. Algumas das vantagens apresentadas pelos alunos foram: i) aprendizagem por meio de colaboração e trabalho em grupo; ii) aprendizagem em contexto real; iii) visualização e investigação dinâmica de fatos matemáticos.

Ndafenongo (2011) investigou como os celulares poderiam ser utilizados no ensino de Matemática. Na pesquisa, foram utilizados cinco video clips sobre o Teorema de Pitágoras. Os mesmos foram enviados para os celulares dos alunos e eram usados em sala de aula apoiando a compreensão do conteúdo abordado. O estudo de caso foi realizado em duas escolas de Ensino Médio, em Grahamstown na África do Sul, envolvendo dois professores de cada escola e um total de 47alunos. A pesquisa sinalizou que os celulares podem ser recursos úteis para apoiar o ensino e aprendizagem em sala de aula, principalmente em escolas com poucos recursos. O uso dos video clips nos celulares contribuiu, segundo o autor, para melhorar a participação e a concentração dos alunos, acelerou o desenvolvimento do conteúdo, incentivou a colaboração e a interação entre colegas e favoreceu a autonomia dos alunos.

Kalloo e Mohan (2012) descrevem um estudo realizado em Trinidade e Tobago, utilizando um aplicativo denominado MobileMath, desenvolvido para testar a hipótese de que m-learning poderia ajudar os estudantes a melhorar o desempenho em Matemática. Sendo destinado ao estudo de Álgebra Elementar, o MobileMath é composto de lições, exemplos, tutoriais, quizzes e fatos curiosos. O uso do aplicativo foi avaliado por um período de três meses com estudantes do ensino secundário, de diferentes escolas, utilizando um mesmo modelo de celular. Os resultados do estudo revelaram melhora no desempenho de alunos, principalmente dos que já tinham feito Álgebra no período anterior (para os que estavam cursando pela primeira vez, o impacto 
não foi tão significativo). Além disso, segundo os autores, foi possível observar o entusiasmado dos alunos com o uso do celular para a aprendizagem.

De maneira geral, os estudos descritos mostram resultados positivos no uso de celulares. No entanto, é preciso considerar que se trata, ainda, de uma área recente de pesquisa.

Finalizando essa seção, duas questões ainda merecem destaque. Uma delas é que celulares com muitas limitações tecnológicas restringem, ou até mesmo inviabilizam, o uso educacional dos mesmos (Batista, 2011). Nesse sentido, a expectativa é que a popularização dos smartphones torne mais prático esse uso. Porém, é importante destacar que, mesmo com smartphones, a escolha de aplicativos exige cuidados, uma vez que muitos são específicos para certos sistemas operacionais (Batista, 2011).

A outra questão refere-se ao fato de diversos projetos de m-learning serem financiados por empresas de telecomunicação. Tais projetos são, sem dúvida, importantes, porém, como alertam Kress e Pachler (2007), não se deve esquecer que o mercado tem regras próprias, que são fortes e permeiam os diversos contextos sociais. Nesse sentido, é preciso atenção, pois os fatores de mercado vão se tornando tão naturais que acabam sendo adotados como modelo de decisão social também na educação (Kress; Pachler, 2007).

O uso do celular no contexto educacional é, portanto, um tema complexo, com pontos positivos e dificuldades a serem consideradas. Entende-se, então, que é preciso discutir a questão com professores, desde a formação inicial, para que os diversos aspectos possam ser refletidos.

Na seção seguinte, são descritos os procedimentos metodológicos adotados em uma pesquisa promovida com alunos de uma Licenciatura em Matemática.

\section{Pesquisa na Licenciatura em Matemática: procedimentos metodológicos}

A pesquisa realizada foi do tipo descritiva ${ }^{3}$, visando captar a opinião dos alunos da Licenciatura em Matemática sobre o uso do celular no contexto educacional.

Para a coleta de dados, foi organizado um questionário que abordou tópicos como: i) possuir, ou não, celular (em caso positivo, questionava-se se o mesmo era um smartphone); ii) experiência de uso educacional do celular (com desdobramentos de novas questões tanto para respostas afirmativas quanto negativas); iii) nível de ensino aconselhável para o uso pedagógico do celular; iv) vivência ou não de situações em que o uso de celular, por parte de colegas, atrapalhou a atenção em sala de aula; v) sugestões para o uso educacional de smartphones.

O questionário foi desenvolvido utilizando-se um formulário do Google Drive ${ }^{4}$. O link do mesmo foi enviado por e-mail para todos os alunos do $2^{\circ}, 4^{\circ}$ e $6^{\circ}$ períodos ${ }^{5}$ da Licenciatura em Matemática de uma instituição federal. No total, havia 16 alunos matriculados no $2^{\circ}$ período, 16 no $4^{\circ}$ e 24 no $6^{\circ}$ período. Todas as turmas foram informadas, presencialmente, da realização da pesquisa e do envio do link do questionário por e-mail. No entanto, apesar do envio para todos os alunos matriculados nos períodos descritos, o questionário foi respondido apenas por 21 professores em formação: nove do $2^{\circ}$ período; sete do $4^{\circ}$ e cinco do $6^{\circ}$ período.

Destaca-se que a análise dos dados foi de cunho qualitativo, não havendo possibilidade de qualquer generalização a partir da mesma, e promovida de maneira global, sem especificações por período.

Na seção seguinte, promove-se a análise e discussão dos dados levantados. 


\section{Resultados e Discussão}

Os 21 alunos da Licenciatura em Matemática, participantes da pesquisa, tinham, em média, 22 anos, com desvio padrão de 2,45, aproximadamente. Do total de alunos, 18 eram do sexo feminino. Todos afirmaram ter celular, no entanto, apenas seis (cerca de 29\%) possuíam smartphone.

Questionados se já haviam utilizado o celular para fins educacionais, aproximadamente 52\% responderam afirmativamente. Aos 10 que responderam negativamente, foram apresentadas as opções mostradas na Tabela 1, solicitando que os mesmos indicassem os principais motivos de nunca terem utilizado (era possível assinalar mais de uma opção). Portanto, na Tabela 1, 100\% dos alunos correspondem a 10 pessoas.

Tabela 1- Motivos para o não uso educacional do celular

\begin{tabular}{l|c}
\hline \multicolumn{1}{c|}{ Motivos } & Alunos (\%) \\
\hline $\begin{array}{l}\text { Os recursos disponíveis no aparelho não favorecem o uso } \\
\text { educacional. }\end{array}$ & 70 \\
\hline Nunca tive interesse em utilizar para esse fim. & 20 \\
\hline $\begin{array}{l}\text { Não considero o celular como um recurso que possa ser útil para } \\
\text { essa finalidade. }\end{array}$ & 0 \\
\hline Outro & 10 \\
\hline
\end{tabular}

Como a maioria dos alunos não possuía smartphone, o percentual da primeira opção da Tabela 1 é bastante natural para o contexto. Até mesmo o aluno que assinalou a opção “Outro" apresentou como motivo o fato do celular não rodar programas. Observa-se, então, que também esse motivo é relativo à falta de recursos no celular que permitam que programas rodem. Assim, a grande maioria justificou o não uso por limitações tecnológicas. Isso sinaliza que, em geral, o fato de nunca ter usado o celular para fins educacionais não foi decorrente de uma rejeição à ideia.

Aos 11 que responderam afirmativamente, foram apresentadas as opções da Tabela 2 , solicitando que as principais formas de uso educacional do celular fossem assinaladas (era possível assinalar mais de uma opção). Portanto, na Tabela 2, 100\% dos alunos correspondem a 11 pessoas.

Tabela 2- Formas de uso educacional do celular

\begin{tabular}{l|c}
\hline \multicolumn{1}{c|}{ Forma } & Alunos (\%) \\
\hline Por meio de aplicativos & 54,55 \\
\hline Pesquisas na Internet & 100,00 \\
\hline Uso de redes sociais & 45,45 \\
\hline Acesso a algum ambiente virtual de aprendizagem & 9,09 \\
\hline Utilização de recursos do próprio celular (fotos, vídeos, etc) & 45,45 \\
\hline Outro & 0 \\
\hline
\end{tabular}

De acordo com os dados da Tabela 2, para os 11 alunos considerados, a realização de pesquisas na Internet é a forma mais usual de uso educacional do celular. Os aplicativos receberam o segundo melhor percentual, sem, no entanto, obter um valor muito expressivo. Para os seis alunos que assinalaram a opção "Por meio de aplicativos”, foi solicitado que mencionassem a finalidade de algum(ns) recursos(s) utilizado(s). A Tabela 3 mostra os dados levantados, sendo $100 \%$ dos alunos correspondentes a seis pessoas. 
Tabela 3 - Aplicativos utilizados para fins educacionais

\begin{tabular}{l|c}
\hline \multicolumn{1}{c|}{ Tipo de aplicativo } & Alunos (\%) \\
\hline Plotadores gráficos & 66,67 \\
\hline Calculadoras & 33,33 \\
\hline Aplicativo para estudo de Cálculo Diferencial e Integral & 33,33 \\
\hline Leitores de arquivos & 33,33 \\
\hline Tradutor & 16,67 \\
\hline
\end{tabular}

Os plotadores gráficos são recursos que podem apoiar o estudo de diversos conteúdos matemáticos. Atribui-se a esse fato o melhor percentual obtido pelos mesmos.

A todos que responderam afirmativamente em relação ao uso educacional de celulares (11 alunos), foi pedido que listassem pontos positivos e negativos de tal uso. Os pontos positivos mais destacados foram: i) praticidade para transportar; ii) popularização (a maioria dos alunos possui); iii) possibilidade de conexão à Internet, quando necessário. Com relação aos pontos negativos, a distração proporcionada pelo uso desses dispositivos foi citada pela maioria. Além deste, o tamanho da tela foi também destacado. Observa-se que tais dados estão coerentes com o referencial teórico discutido anteriormente.

A todos os 21 alunos participantes da pesquisa foi proposta a questão abaixo, cujas alternativas são apresentadas na tabela 4 (dentre as quais era possível escolher uma única opção). Na tabela 4, portanto, 100\% dos alunos correspondem a 21 pessoas.

"Alguns estados e municípios brasileiros ${ }^{6}$ possuem leis proibindo o uso do celular em sala de aula, pois o mesmo compromete a atenção dos alunos nas atividades. Há ressalvas, em diversos casos, para o uso pedagógico desses equipamentos. Como futuro professor, você considera que a utilização do celular em alguma ação pedagógica, em sala de aula, é aconselhável:”

Tabela 4 - Níveis de Ensino apropriados para o uso pedagógico do celular

\begin{tabular}{l|c}
\hline \multicolumn{1}{c|}{ Níveis de Ensino } & Alunos (\%) \\
\hline Somente no Ensino Superior & 9,52 \\
\hline No Ensino Médio e no Superior & 33,33 \\
\hline A partir do segundo ciclo do Ensino Fundamental & 33,33 \\
\hline Desde o primeiro ciclo do Ensino Fundamental & 19,05 \\
\hline Em nenhum nível de ensino & 4,77 \\
\hline
\end{tabular}

A cada participante foi solicitada uma justificativa para a opção assinalada na Tabela 4. Algumas dessas são apresentadas a seguir. Ressalta-se que, para a análise dos dados, os alunos foram denominados A, B, C, ... , sendo assim indicados neste trabalho.

Os dois alunos que selecionaram a opção "Somente no Ensino Superior" justificaram da seguinte forma:

Porque no ensino superior, pelo menos teoricamente, as pessoas são mais maduras. Elas sabem que o mau rendimento delas na faculdade, comprometerá sua vida profissional, costumam ser mais interessadas nos estudos. Isso não acontece com crianças e adolescentes, que estão estudando porque são "obrigadas" e em qualquer oportunidade com o celular à mão, navegariam ou fariam coisas diferentes das quais eram para ser feitas (Aluno D).

Considero importante o aluno ter maturidade sobre o uso do celular para fins pedagógicos, para que o aparelho não se torne apenas uma tecnologia de entretenimento (Aluno P). 
Sete participantes da pesquisa selecionaram a opção "No Ensino Médio e no Superior”. Abaixo são apresentadas três justificativas:

Pois os alunos estão mais maduros nessa fase, podendo assim usar o celular como um recurso didático (Aluno E).

Acredito que se for feito de forma correta, é possível chamar a atenção dos alunos de ensino médio para o uso adequado do celular em sala de aula. Acho que a maturidade para fazê-lo surge nessa faixa etária (Aluno F).

O celular, usado de forma correta, pode ser utilizado como uma ferramenta de aprendizagem sim, pois o mesmo já faz parte do cotidiano da maioria dos alunos. Deve-se levar em consideração a maturidade dos alunos, então acredito que a partir do ensino médio esse trabalho é mais fácil e eficaz (Aluno I).

Sete alunos também selecionaram a opção "A partir do segundo ciclo do Ensino Fundamental”. A seguir, são apresentadas três justificativas:

A partir do $5^{\circ}$ ano acredito que o aluno já tenha um pouco mais de cuidado com o celular e acredite que o celular pode ser um recurso educacional (Aluno J).

Porque nessa idade os alunos tem muito interesse pelo celular, e se o celular for utilizado em sala de aula vai tornar a aprendizagem mais interessante para eles (Aluno M).

Visto que as crianças já nascem na era digital e são nativos digitais, trabalhar com a tecnologia é muito mais fácil e prático para eles, daí seria interessante conscientizar o aluno sobre o uso do celular para fins educacionais, assim acho que a partir do segundo ciclo do Ensino Fundamental a criança já é capaz de compreender isso (Aluno U).

Dos quatro participantes da pesquisa que selecionaram a opção "Desde o primeiro ciclo do Ensino Fundamental”, foram selecionadas as duas justificativas abaixo:

As crianças possuem muita facilidade em utilizar o aparelho celular, sendo assim, o seu uso em sala de aula pode fazer do aprendizado algo mais atraente e significativo para eles (Aluno K).

O celular pode sim ser uma ótima ferramenta de auxílio na aprendizagem, é um tipo de aparelho que a maioria das pessoas possui, até mesmo as crianças, então porque não utilizá-lo? É um recurso que a escola não precisará comprar, e há várias maneiras de utilizá-lo para ensinar (Aluno L).

Um único aluno selecionou a opção “Em nenhum nível de ensino”, justificando como abaixo:

Creio que muitos alunos não possuem maturidade para estarem utilizando tal dispositivo (Aluno Q).

A posição dos participantes da pesquisa sobre os níveis de ensino em que o uso do celular seria aconselhável reflete bem a complexidade da questão. Há opiniões diversas e, ainda assim, bem coerentes, permitindo observar que se trata de um tema com pontos positivos, mas, também, com aspectos negativos, o que dificulta um consenso. No entanto, os dados sinalizam que os pontos positivos, na visão dos participantes da pesquisa, superam as dificuldades, pois apenas um aluno considerou que o uso do celular não é viável em qualquer nível de ensino. Destaca-se que a palavra maturidade foi citada por diversos participantes, o que sinaliza a preocupação com as distrações que o uso desse dispositivo pode ocasionar.

Questionados quanto a já ter vivenciado, como aluno do ensino superior, situações em que o uso do celular por parte de algum colega atrapalhou a atenção na aula, os 
participantes da pesquisa responderam como mostra a Tabela 5. Na mesma, 100\% dos alunos correspondem a 21 pessoas.

Tabela 5 - Uso do celular de um colega já atrapalhou a atenção

\begin{tabular}{c|c}
\hline Opções & Alunos (\%) \\
\hline Sim & 61,90 \\
\hline Não & 38,10 \\
\hline
\end{tabular}

Observa-se que, mesmo no Ensino Superior, o uso inadequado do celular pode ocasionar distrações. Abaixo, são apresentados os comentários de três dos 13 alunos que responderam afirmativamente na tabela 5 :

Música alta, aplicativos bobos com som, etc. (Aluno A).

É muito chato quando toda a turma está concentrada em alguma atividade ou num momento de avaliação, e algum celular toca (Aluno Q).

Quando um colega estava navegando no facebook pelo celular durante a aula e me chamou pra mostrar-me algo. Tirou minha atenção no meio da explicação (Aluno S).

Encerrando o questionário, foram solicitadas sugestões para uso educacional do smartphone. A seguir, são apresentadas quatro dessas sugestões:

Acho que pode ser legal, mas não aconselharia em todas as aulas $e$ que fosse permitido o uso quando o professor autorizasse (Aluno A).

$O$ uso deveria ser liberado para todos os alunos e os professores deveriam ser treinados para educar seus alunos em relação ao uso (Aluno C).

Os professores sugerirem jogos ou aplicativos que possam ser utilizados a fim de ajudar na compreensão da matéria ou aplicação do conteúdo. Pode ser muito útil, se seu uso for bem orientado (Aluno D).

Que seja utilizado de forma correta, com maturidade e com os recursos corretos. Tudo quando é bem feito, é válido (Aluno F).

As respostas dos participantes da pesquisa, embora não permitam qualquer generalização, possibilitam captar a visão de um grupo de jovens diretamente relacionados ao contexto educacional. Os mesmos não são estudiosos do assunto, nem mesmo têm efetiva experiência com ações em m-learning, mas as respostas apresentadas foram coerentes com o que, em geral, é discutido na literatura da área sobre os celulares no contexto educacional.

\section{Considerações Finais}

Na sociedade atual, as tecnologias digitais móveis permeiam as mais diversas áreas profissionais, o que inclui o setor educacional. Assim, é importante que a formação de professores incorpore discussões sobre o uso dessas tecnologias no contexto educacional, tendo em vista a preparação de profissionais mais conscientes.

O uso do celular é, em particular, uma questão que ainda apresenta dificuldades diversas, que devem ser discutidas. A proibição do uso desses dispositivos em sala de aula pode nem mesmo impedir a ocorrência de problemas, pois os alunos driblam, muitas vezes, as restrições. Trata-se de uma questão ampla, que requer bom senso e diálogo, mesmo que seja apenas para justificar os motivos da proibição.

É fundamental também ponderar que mesmo em outros setores os celulares também podem ocasionar problemas. A distração relacionada ao uso desses dispositivos pode, por exemplo, afetar o trabalho, o convívio pessoal e, até mesmo, o lazer. Portanto, é um tema que requer reflexões mesmo fora dos limites do contexto educacional. 
Por outro lado, é inegável que a praticidade de ter sempre à mão um equipamento com inúmeras funções, como as dos smartphones, é importante em diversos momentos da vida atual. Entende-se, então, que, se utilizados adequadamente, esses dispositivos também podem trazer contribuições para ações educacionais.

Finalizando, destaca-se que, em trabalhos futuros, alunos de outros cursos e níveis de ensino, assim como pais de alunos do Ensino Fundamental e Médio, poderão ser consultados, a respeito do uso pedagógico do celular, expandindo a análise feita neste trabalho.

\footnotetext{
Notas de Texto

${ }^{1}$ Para Quinn (2011), o celular é um verdadeiro dispositivo móvel, pois está sempre com o usuário.

${ }^{2}$ Os aplicativos para celular utilizados no referido estudo de caso pertencem ao projeto Math4Mobile (http://www.math4mobile.com/).

${ }^{3}$ Segundo Gil (2008), pesquisas descritivas buscam apresentar características de uma população, fenômeno ou de uma experiência ou, então, estabelecer relações entre variáveis.

${ }^{4}$ Serviço de armazenamento, sincronização e compartilhamento de arquivos on-line, da empresa Google, que oferece diversas aplicações de produtividade, como formulários, planilhas e apresentações, entre outros.

${ }^{5} \mathrm{Na}$ licenciatura considerada, a entrada de alunos é anual, sendo assim em um semestre há apenas períodos pares e, em outro, períodos impares.

${ }^{6}$ Tais como Estado de São Paulo (Lei estadual 12730, de 2007), Estado do Rio de Janeiro (Lei estadual 5453, de 2009), Recife/PE (Lei municipal 17837, de 2012), Mossoró/RN (Lei municipal 2829, de 2012).
}

\section{Referências Bibliográficas}

BATISTA, S. C. F. M-LearnMat: Modelo Pedagógico para Atividades de Mlearning em Matemática. Tese (doutorado em Informática na Educação). Porto Alegre, RS, Universidade Federal do Rio Grande do Sul - UFRGS, 2011.

BAYA'A, N.; DAHER, W. Students' perceptions of Mathematics learning using mobile phones. In: INTERNATIONAL CONFERENCE ON MOBILE AND COMPUTER AIDED LEARNING, 4., 2009, Amman, Jordan. Proceedings. Disponível em: $<$ http://staff.najah.edu/sites/default/files/Students\%20Perceptions\%20of\%20Mathemati cs\%20Learning\%20Using\%20Mobile\%20Phones.pdf> Acesso em: 07 mar. 2013.

EDUCAUSE. 7 Things You Should Know about Mobile Apps for Learning. 2010. Disponível em: <http://net.educause.edu/ir/library/pdf/ELI7060.pdf>. Acesso em: 02 jan. 2013.

GIL, A. C. Como elaborar projetos de pesquisa. São Paulo: Atlas, 6. ed., 2008. KALLOO, V.; MOHAN, P. MobileMath: an innovative solution to the problem of poor Mathematics performance in the Caribbean. Caribbean Teaching Scholar. v. 2, n. 1, p. 5-18, April 2012.

KRESS, G.; PACHLER, N. Thinking about the ' $\mathrm{m}$ ' in m-learning. In: PACHLER, $\mathrm{N}$. (Ed.). Mobile learning: towards a research agenda. London, UK: WLE Centre/ Elanders Hindson Ltd, 2007. p. 7-32.

MACHADO, J. L. A. Celular na Escola: O que fazer? 2012. Disponível em: $<$ http://cmais.com.br/educacao/celular-na-escola-o-que-fazer $>$. Acesso em: 10 jan. 2013.

NDAFENONGO, G. An investigation into how cell phones can be used in the teaching of Mathematics using Vitalmaths video clips: a case study of 2 schools in Grahamstown, South Africa. Thesis (degree of Master of Education). Grahamstown, South Africa, Rhodes University (Faculty of Education). December, 2011. 
PACHLER, N.; BACHMAIR, B.; COOK, J. Mobile Learning: Structures, Agency, Practices. New York, USA: Springer, 2010.

QUINN, C. N. Mobile Learning: Landscape and Trends. 2011. Disponível em: <https://commons.lbl.gov/download/attachments/77828943/mobile2011report-f2.pdf>. Acesso em: 12 jan. 2013.

ROBLES, G.; GONZÁLEZ-BARAHONA, J. M.; FERNÁNDEZ-GONZÁLEZ, J. Implementing Gymkhanas with Android smartphones: A multimedia m-learning game. In: IEEE GLOBAL ENGINEERING EDUCATION CONFERENCE (EDUCON), 4-6, April, Amman, Jordan. Proceedings. 2011.

SCHMIEDL, G.; GRECHENIG, T.; SCHMIEDL, B. Mobile enabling of virtual teams in school: an observational study on smart phone application in secondary education. In: INTERNATIONAL CONFERENCE ON EDUCATION TECHNOLOGY AND COMPUTER, 2, June, Shanghai, China. Proceedings. IEEE Xplore Digital Library, 2, 74-79, 2010.

SEABRA, C. O celular na sala de aula. 2013. Disponível em: <http://cseabra.wordpress.com/2013/03/03/o-celular-na-sala-de-aula/>. Acesso em: 20 abr. 2013.

UNESCO (2012). Turning on Mobile Learning in Latin America: Illustrative Initiatives and Policy Implications, Working Paper Series on Mobile Learning, Paris, France, http://unesdoc.unesco.org/images/0021/002160/216080e.pdf, 28 jun. 2012.

XIE, A.; ZHU, Q.; XIA, H. Investigating College Major Differences in the Need of Mobile Phone Learning. In: INTERNATIONAL CONFERENCE ON MULTIMEDIA TECHNOLOGY (ICMT), July, Hangzhou, China. 2011. Proceedings. 2011. 